\title{
Gambaran Pengetahuan Ibu tentang Persiapan Fisik dan Psikis Memasuki Masa Menopause
}

\author{
Cynthia Ramadhan Asriati ${ }^{1}$, Merry Wijaya ${ }^{2}$, Sefita Aryuti Nirmala ${ }^{3}$, Sharon \\ Gondodiputro ${ }^{4}$, Lina Rahmiati ${ }^{5}$
}

Program Studi D-IV Kebidanan, Fakultas Kedokteran, Universitas Padjadjaran ${ }^{1}$

Departemen Ilmu Kesehatan Masyarakat, Fakultas Kedokteran, Universitas Padjadjaran ${ }^{2,3,5}$ bidunpad.2014.025@gmail.com ${ }^{1}$

\section{Diajukan 6 Desember 2018 Diperbaiki 29 Mei 2019 Diterima 29 Mei 2019}

\section{ABSTRAK}

Latar Belakang: Menopause merupakan hal fisiologis bagi setiap wanita. Wanita menopause akan mengalami beberapa keluhan baik secara fisik maupun psikis. Gejala yang dialami wanita menjelang menopause menyebabkan ketidaksiapan ibu tentang perubahan fisik maupun psikis. Untuk mengurangi hal tersebut wanita harus mempersiapkan diri baik secara fisik maupun psikis dalam menghadapi menopause.

Tujuan: Penelitian ini bertujuan untuk mengetahui gambaran pengetahuan ibu tentang persiapan fisik dan psikis memasuki masa menopause di wilayah kerja Puskesmas Soreang.

Metode: Desain penelitian deskriptif dengan pendekatan cross sectional. Sampel penelitian ini sebanyak 80 orang ibu yang berusia $40-45$ tahun dengan pengambilan sampel menggunakan teknik multistage random sampling. Instrumen penelitian menggunakan kuesioner.
Hasil: Hasil penelitian menunjukkan bahwa sebagian besar responden yang memiliki tingkat pendidikan SLTA sebanyak (46,3\%), jumlah paritas 1 - 2 anak sebanyak (56,3\%), sedangkan responden yang tinggal bersama suami dan anak sebanyak 68 responden (85\%). Gambaran pengetahuan tentang persiapan fisik dan persiapan psikis memasuki masa menopause masih dikatakan cukup, yaitu sebesar $(67,5 \%)$ pengetahuan persiapan fisik dan (65\%) pengetahuan persiapan psikis.

Kesimpulan: Ibu di wilayah kerja Puskemas Soreang memiliki pengetahuan persiapan fisik dan psikis menopause dalam kategori cukup, sehingga diharapkan peran aktif dari petugas kesehatan dalam penyuluhan, memberikan informasi persiapan menopause, serta ibu aktif dalam kegiatan poswindu agar meningkatkan pengetahuan tentang persiapan fisik dan psikis menopause.

Kata Kunci: pengetahuan; persiapan fisik dan psikis; menopause

\section{ABSTRACT}

Background: Menopause is physiological for women. Women who face menopause will experience both physical and psychological complaints. The symptoms experienced by women in the days leading up to the menopause causing women to feel unprepared about the physical and psychological changes of menopause. To reduce this, women should prepare themselves physically and psychologically in dealing with menopause.

Objective: This study aimed to determine the description of mother's knowledge about physical and psychological preparation entering the menopause period in the working area of Soreang Community Health Center.

Methods: This research was descriptive research with cross sectional approach. The samples of this research were 80 people aged 40 - 45 years by using Cluster Sampling technique. The instrument used was questionnaire.

Results: The results of this study indicated that the highest percentage of education level of respondents was senior high school level (46.3\%), the number of parity is not much different from 1 to 2 children (56.3\%). The highest percetage of the residence type was living together with husband and child (85\%). The description of knowledge is sufficiently categorized (67.5\%) of physical knowledge and (65\%) knowledge of psychological preparation.

Conclusions: Mothers in the Soreang Community Health Center work area have knowledge of menopausal physical and psychological preparation in sufficient categories, so the active role of health officials was expected to be able to provide counseling or provide information about preparation of menopause. On the onther hand, mothers who were active in poswindu was expected to further improve the knowledge about menopause preparation.

Keywords: Knowledge; Physical and Psychological Preparation; Menopause 


\section{PENDAHULUAN}

Menopause akan dialami oleh semua wanita yang hidup sampai usia tua. Menopause merupakan hal fisiologis bagi wanita seiring dengan bertambahnya usia karena adanya perubahan hormon estrogen. Menopause didefinisikan sebagai keadaan tidak adanya periode menstruasi selama 12 bulan, namun secara umum menopause dapat dikatakan sebagai berakhirnya siklus menstruasi pada wanita.

Menurut Badan Pusat Statistik pada tahun 2014, jumlah total penduduk wanita di Indonesia sebanyak 125.202.594 penduduk. Data dari Badan Pusat Statisik Jawa Barat, jumlah total penduduk wanita di Jawa Barat pada tahun 2015 sebanyak 23.028.642 jiwa atau sekitar $48.85 \%$ dengan rentang usia 45-50 tahun sebanyak 1.397 .871 atau $7,6 \%$ penduduk. Semakin bertambahnya usia seorang wanita, maka semakin berkurang fungsi dari tubuhnya termasuk hormon-hormon akan menurun secara perlahan-lahan.

Wanita yang akan mengalami menopause melewati tahapan terlebih dahulu diantaranya pramenopause, perimenopause, menopause, dan pascamenopause, serta umumnya menopause terjadi pada wanita usia 45-50 tahun.

(Greenblum, Rowe, Neff, \& JS, 2013) meneliti tentang "Hubungan Pengaturan Emosi Positif dengan Kecemasan Menjelang Menopause pada Perempuan Pekerja" dan hasilnya menjelaskan bahwa $80 \%$ wanita melaporkan mengalami bermacam-macam gangguan fisik dan psikis menjelang menoupause.

Gejala fisik diantaranya berkeringat dimalam hari, gangguan tidur, kekeringan vagina, sakit kepala, dan penurunan berat badan, sedangkan gejala psikis yang sering terjadi diantaranya kelelahan, cepat marah, dan kecemasan. Adapun keluhan yang memiliki dampak tertinggi yaitu pada gangguan tidur dan kekeringan vagina dengan presentase 9,7\% dan keluhan individu lainnya termasuk kelelahan dan kecemasan dengan presentase $16,7 \%$.
Hasil penelitian (Widjayanti, 2016) tentang "Keluhan Akibat Penurunan Kadar Hormon Estrogen" didapatkan 90.32\% responden mengeluhkan rasa tidak nyaman pada tulang, persendian dan otot, $85.87 \%$ responden mengeluhkan hot flushes dan $74.19 \%$ responden mengeluhkan kelelahan secara fisik dan mental akibat penurunan kadar estrogen pada masa menopause.

Keluhan tesebut bisa diatasi dengan persiapan fisik dan persiapan psikis. Untuk keluhan nyeri tulang, sendi, dan otot bisa dilakukan dengan mengkonsumsi kalsium dan digabung dengan asupan vitamin D. Para ahli merekomendasikan $1500 \mathrm{mg}$ perhari untuk asupan kalsium.

Persiapan diri menuju menopause dapat dilakukan dengan makan makanan yang mengandung kacang-kacangan terutama kacang kedelai, serta dapat ditemukan pada hampir semua jenis sayuran, tahu, pepaya, dan tanaman lain serta susu kedelai. Adapun yang harus dilakukan oleh wanita menjelang masa menopause dapat berupa olahraga, seperti jalan kaki, jogging, dan yoga yang berfungsi untuk menjaga kepadatan tulang.

Adanya perubahan hormon dan keluhan-keluhan pada wanita usia lanjut te r s ebut a kan me m pengaruhi ketidaknyamanan wanita. Untuk itu penting mengetahui perubahan dan gejala-gejala akibat perubahan tesebut agar dapat mempersiapkan diri baik secara fisik maupun psikis untuk menjelang masa menopause.

\section{METODE}

Penelitian ini bersifat survei deskriptif dengan pendekatan cross sectional untuk mengkaji gambaran pengetahuan ibu tentang persiapan fisik dan psikis memasuki masa menopause di wilayah kerja Puskesmas Soreang.

Populasi dalam penelitian ini adalah WUS yang sudah menikah berusia $40-45$ tahun sebanyak 1200 di wilayah kerja Puskesmas Soreang. Kriteria inklusi pada penelitian ini adalah WUS sehat jasmani dan rohani, bersedia menjadi responden, dan berdomisili di wilayah 
kerja Puskesmas Soreang, dan WUS yang sudah menikah berusia 40 - 45 tahun. Kriteria eksklusi pada penelitian ini adalah wanita usia subur yang menggunakan kb hormonal serta wanita yang sedang masa nifas dan histerektomi. Setelah diberikan kriteria inklusi dan eksklusi, jumlah responden menjadi 80 responden.

Teknik pengambilan sampel pada penelitian ini adalah teknik cluster random sampling. Ketika jumlah sampel didapat, pengambilan sampel dilakukan dengan teknik consecutive sampling. Adapun jumlah sampel tiap desa yang berada di wilayah kerja Puskesmas Soreang yaitu desa pamekaran 14 orang, Desa Soreang 17 orang, Desa Parung Serab 15 orang, Desa Sekarwangi 13 orang, Desa Panyirapan 11 orang, dan Desa Cingcin 10 orang.

Instrumen penelitian ini menggunakan kuesioner yang sudah dilakukan uji validitas dan reliabilitas terlebih dahulu kepada 20 responden yang berkarakteristik sama dengan responden yang akan digunakan pada penelitian.

Hasil uji validitas dari 12 pernyataan persiapan fisik yang mendapatkan nilai koefisien validitas antara 0,4446 - 0,693 sebanyak 12 pernyataan, sedangkan pernyataan persiapan psikis yang mendapatkan nilai koefisien validitas antara 0,4445 - 0,674 sebanyak 12 item pernyataan. Sehingga masing - masing item pernyataan untuk mengukur pengetahuan fisik dan psikis ibu dinyatakan valid dan hasil perhitungan uji reliabilitas variabel pengetahuan persiapan fisik dan psikis dikatakan reliabel karena cronbach's alpha lebih dari 0,6.

Analisis data yang digunakan yaitu univariat. Penelitian telah mendapatkan izin dari Komite Etik Fakultas Kedokteran Universitas Padjadjaran dengan nomor etik 094/UN6.C10/PN/2017.

\section{HASIL DAN PEMBAHASAN}

Tabel 1. Karakteristik Subjek Penelitian

\begin{tabular}{|c|c|c|c|}
\hline \multirow[t]{2}{*}{ No } & \multirow[t]{2}{*}{ Karakteristik } & \multicolumn{2}{|c|}{$\begin{array}{c}\text { Karakteristik Subjek } \\
\text { Penelitian }\end{array}$} \\
\hline & & đ́́̆ ÜKK & ÊĪ \\
\hline $\bar{A}$ & 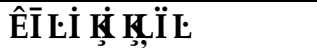 & $\mathrm{A}$ & A \\
\hline 1. & SD & 13 & 16,3 \\
\hline 2. & SLTP & 20 & 25 \\
\hline 3. & SLTA & 37 & 46,3 \\
\hline & $\begin{array}{l}\text { Perguruan Tinggi } \\
\text { Paritas }\end{array}$ & 10 & 12,5 \\
\hline 1. & $1-2$ & 45 & 56,3 \\
\hline 2. & $\begin{array}{l}3 \text { atau lebih } \\
\text { Tempat Tinggal }\end{array}$ & 35 & 43,8 \\
\hline 1. & Dengan Suami & 7 & 8,8 \\
\hline 2. & Dengan Anak & 5 & 6,3 \\
\hline 3. & $\begin{array}{l}\text { Dengan Suami dan } \\
\text { anak }\end{array}$ & 68 & 85 \\
\hline
\end{tabular}

Dilihat dari tabel 1 , sebanyak 37 responden $(46,3 \%)$ yang berpendidikan SLTA, dan masih terdapat $16,3 \%$ yang berpendidikan SD. Apabila dilihat dari paritas, responden yang memiliki paritas 1 - 2 sebanyak 45 responden $(56,3 \%)$ serta yang memiliki paritas 3 atau lebih sebanyak 35 responden (43,8\%).

Responden pada penelitian ini lebih banyak tinggal bersama dengan suami dan anak yaitu sebanyak 68 responden (85\%) dan hanya sebagian kecil responden yang tinggal hanya dengan anak yaitu sebanyak 5 responden $(6,3 \%)$ atau hanya dengan suami saja sebanyak 7 responden $(8,8 \%)$.

Tabel 2 Distribusi Frekuensi Pengetahuan Ibu Tentang Persiapan Fisik dan Psikis di Wilayah Kerja Puskesmas Soreang

No Pengetahuan

Pengetahuan Persiapan Fisik dan Psikis

Jumlah Persentase

\begin{tabular}{|c|c|c|c|}
\hline \multicolumn{4}{|c|}{ Pengetahuan Fisik } \\
\hline 1. & Baik & 18 & 22,5 \\
\hline 2. & Cukup & 54 & 67,5 \\
\hline 3. & Kurang & 8 & 10 \\
\hline & Pengeta & & \\
\hline 1. & Baik & 13 & 16,3 \\
\hline 2. & Cukup & 52 & 65 \\
\hline 3. & Kurang & 15 & 18,8 \\
\hline
\end{tabular}


Diketahui dari tabel 2, bahwa pengetahuan ibu tentang persiapan fisik yang mempunyai pengetahuan cukup sebanyak 54 responden $(67,5 \%)$ dan hanya 8 responden $(10 \%)$ yang berpengetahuan kurang. Adapun berdasarkan pengetahuan persiapan psikis tidak jauh berbeda hasilnya yaitu ibu yang berpengetahuan cukup sebanyak 52 responden (65\%) dan berpengetahuan baik sebanyak 13 responden $(16,3 \%)$.

Berdasarkan hasil penelitian yang diperoleh, peneliti memperoleh data yang dijadikan tolak ukur dalam melakukan pembahasan dan dapat dijabarkan sebagai berikut :

\section{A. Pengetahuan Persiapan Fisik}

Pendidikan yang tinggi membuat minat ibu menjadi tinggi untuk mengetahui secara dini persiapan fisik maupun psikis memasuki masa menopause. Dalam penelitian ini pendidikan ibu dibedakan atas ibu yang berpendidikan SD, SLTP, SLTA, dan perguruan tinggi.

Hasil yang didapat sebagian besar memiliki tingkat pendidikan SLTA dan perguruan tinggi sebanyak 47 orang $(48,8 \%)$. Adapun hasil dari tingkat pengetahuan persiapan fisik pada penelitian ini sebanyak 54 orang $(67,5 \%)$ memiliki pengetahuan cukup.

Semakin tinggi pendidikan ibu, hasil yang diharapkan memiliki pengetahuan baik. Pendidikan merupakan suatu usaha seseorang untuk mendapatkan pengetahuan atau ilmu dan dapat mengembangkan kemampuan di dalam dan di luar sekolah.(Notoatmodjo, 2015) menyatakan tingkat pendidikan dapat mempengaruhi tingkat pengetahuan individu dalam menerima informasi khususnya bidang kesehatan.

Secara umum, ada faktor yang mempengaruhi pengetahuan, diantaranya faktor internal (pengetahuan dalam diri WUS) dan eksternal (pengaruh dari luar) dimana faktor internal sendiri ibu sudah mengetahui pengetahuan dari persiapan menopause, sedangkan eksternal dipengaruhi oleh lingkungan yang mempengaruhi pengetahuan ibu. Hal ini tidak sebanding dengan teori yang dikemukakan oleh Notoatmodjo.

Tingkat pendidikan tinggi atau rendah pada setiap wanita memiliki peluang yang sama dalam mendapatkan pengetahuan tentang persiapan menopause karena persiapan untuk memasuki masa menopause dapat dipengaruhi oleh faktor diantaranya pengetahuan, hubungan interpersonal, maupun keluarga.

Untuk itu, seorang ibu perlu mencari informasi mengenai persiapan fisik menjelang menopause dan mengaplikasikannya. Hal yang bisa dilakukan untuk menghadapi menopause terutama dalam persiapan fisik yaitu berolahraga secara teratur untuk meningkatkan kekuatan tulang dengan melakukan berjalan kaki, joging, dan berenang.

Makanan yang perlu dikonsumsi ialah makanan yang kaya akan kalsium, seperti susu, keju, dan kacang-kacangan yang dapat mengurangi keropos tulang, konsumsi makanan yang mengandung vitamin seperti buah dan sayuran, dapat mengurangi air teh, kopi, soda maupun minuman alkohol karena dapat memperlambat penyerapan kalsium.

Apabila dilihat dari paritas, responden yang memiliki 1 - 2 anak sebanyak 45 orang $(56,3 \%)$ dan hasil ini tidak berbeda jauh dengan responden yang memiliki anak 3 atau lebih sebanyak 35 orang $(43,8 \%)$.

Hasil penelitian (Safitri, 2009) tentang faktor-faktor yang mempengaruhi pada wanita Menopause di Kelurahan Titi Papan Kota Medan menyatakan bahwa jumlah anak berpengaruh terhadap masa menopause. Semakin sering wanita melahirkan maka semakin tua atau lama mereka memasuki memasuki menopause. Hal ini berkaitan dengan sistem reproduksi wanita, maka dari itu ibu harus lebih mempersiapkan dirirnya menjelang menopause.

Hasil penelitian ini menunjukkan bahwa ibu yang tinggal dengan suami dan anak sebanyak 68 orang (85\%). Ketika ibu tinggal bersama keluarganya, seharusnya mendapat dukungan dari keluaga dalam menghadapi 
menopause. Dalam hal ini, keluarga perlu mendukung mengenai perubahan yang terjadi pada wanita menjelang menopause serta mengingatkan kepada ibu tentang pengetahuan yang diketahuinya untuk diaplikasikan.

\section{B. Pengetahuan Persiapan Psikis}

Menurut hasil penelitian ini, ibu yang berpengetahuan tentang perubahan psikis yang cukup sebanyak 52 orang (65\%) dan ibu yang tinggal bersama suami dan anak sebanyak 68 orang (85\%). Semakin banyak dukungan keluarga, seharusnya ibu memiliki pengetahuan yang baik. Akan tetapi apabila dilihat dari hasil penelitian tentang tingkat pengetahuan yang baik hanya terdapat 13 orang $(16,3 \%)$.

Hal tersebut bisa dipengauhi oleh faktor eksternal yang sangat berperan terhadap psikologis ibu. Beberapa wanita ketika menghadapi menopause memiliki perubahan psikis yang membuat merasa tertekan, menganggap dirinya tidak berguna lagi, merasa tidak dapat memenuhi kebutuhan seksual suami, dan merasa memberatkan keluarga dan orang lain.

Perlu diberikan petunjuk kepada ibu untuk mempersiapkan kondisi psikis menuju masa menopause seperti bersosialisasi, mengikuti aktivitas menyenangkan, memperbanyak lawan bicara, mengurangi stress seperti meditasi, mengikuti kegiatan keagamaan, dan mencari teman yang mempunyai kemampuan untuk membantu dan menceritakan hal yang sama dialami. Suami dan anak diberikan informasi mengenai perubahan psikis untuk mempersiapkan yang harus dilakukan ketika menopause terjadi pada ibunya.

Hasil penelitian pada responden dengan jumlah paritas responden 1 - 2 anak serta 3 atau lebih menunjukkan hasil tidak jauh berbeda yaitu sebanyak 45 orang (56,3\%) dan 35 orang $(43,8 \%)$. Menurut penelitian (Susanti, 2014) keluarga penyebab psikologis dan kecemasan dikarenakan tidak ada dukungan misalnya wanita ditinggal anak menjalankan pendidikan atau ditinggal berkeluarga hal tersebut dapat mempengaruhi kondisi psikis ibu.

WUS menjelang menopause banyak mengalami perubahan dalam tubuhnya. Perubahan tersebut mempengaruhi psikis diantaranya mempunyai perasaan takut ditinggal suami, merasa sudah tidak berguna sehingga dibutuhkan perhatian agar kondisi psikis ibu dalam keadaan baik.

Melihat dari hasil ini, persentase ibu yang bertempat tinggal dengan suami dan anak sebanyak 68 orang (85\%). Dilihat dari hasil penelitian, bahwa banyak ibu yang tinggal dengan suami serta anaknya artinya ibu tetap mendapatkan dukungan dari keluarga.

Peneliti dapat mengatakan bahwa dalam menjaga kondisi psikis dan kecemasan WUS dalam menghadapi menopause sangat butuh peran dari keluarga. Dukungan dari keluarga diharapkan dapat merubah psikis WUS sedikit menghilang.

Keterbatasan dalam penelitian ini adalah kebutuhan dana karena sampel yang banyak membutuhkan pemberian kuesioner yang banyak. Selain itu, responden perlu meluangkan waktu $\pm 10-15$ menit untuk mengisi kuesioner.

\section{KESIMPULAN DAN SARAN}

\section{A. Kesimpulan}

1. Hasil ibu yang berpengetahuan tentang persiapan fisik memasuki masa menopause yaitu kategori berpengetahuan baik sebanyak $22,5 \%$ responden, pengetahuan cukup sebanyak $67,5 \%$ responden, dan pengetahuan yang kurang sebanyak $10 \%$ responden.

2. P e r s e n t a s e i b u y a n g berpengetahuan tentang persiapan psikis memasuki masa menopause kategori pengetahuan baik sebanyak $16,3 \%$ responden, pengetahuan cukup sebanyak $65 \%$ responden, dan pengetahuan yang kurang sebanyak $18,8 \%$ responden. 


\section{B. Saran}

Tenaga Kesehatan agar dapat memberikan penyuluhan atau memberikan informasi yang akurat sesuai kebutuhan ibu khususnya tentang persiapan menopause.

Mendorong ibu untuk memulai mencari informasi tentang persiapan memasuki masa menopause sehingga dapat mengetahui dan mempersiapkan diri dalam menghadapi menopause.

\section{DAFTAR PUSTAKA}

Anita Rahmawati Yani Widyaastuti Y, E. (2009). Kesehatan reproduksi. Yogyakarta.: Fitramaya.

Ghani L. (2009). Media Peneliti dan Pengembang Kesehatan. Menopause. 2009; XIX.

Greenblum, C., Rowe, M., Neff, D., \& JS, G. (2013). Midlife Women: Symptoms Associated with Menopausal Transition and Early Postmenopause and Quality of Life. Menopause: The Journal of The North American Menopause Society. 20(1): 22-27. $\mathrm{R}$ e $\mathrm{t} \mathrm{r}$ i e $\mathrm{v}$ e d $\mathrm{f} \mathrm{r}$ o $\mathrm{m}$ https://doi.org/10.1097/gme.0b013e31 $825 a 2 a 91$

Heni, Susanti. (2014). Hubungan Dukungan Suami dengan Tingkat Kecemasan Istri dalam Menghadapi Menopause. Biometrika dan Kependudukan, Vol 3. No.2: 114-119. Desember 2014.

Kementerian Kesehatan RI. (2015).
Sekretariat Jenderal Profil Kesehatan Indonesia Tahun 2014. Jakarta: Kementerian Kesehatan RI.

Kuswita. (2012). Gambaran Pengetahuan Wanita Tentang Masa Menopause. Vol 20.

Maftukhatus Syarrifah ES. (2011). Hubungan Pengaturan Emosi Positif dengan Kecemasan Menjelang Menopause pada Perempuan Pekerja. Humanitas. 11-2:143-51.

Varneym H, M.Kriebs J, Gegor CL. (2010). Nutrisi selama menopause dan sesudahnya: Jakarta.

Notoatmodjo, S. (2015). Metodologi Penelitian Kesehatan. Semarang: Rineka Cipta.

Safitri, A. (2009). Faktor-Faktor Mempengaruhi Menopause Pada Wanita di Kelurahan Titi Papan Kota Medan Tahun 2009. Skripsi. Fakultas Ilmu Kesehatan dan Keperawatan Universitas Sumatra Utara: Medan.

Susanti, E. H. (2014). Hubungan Dukungan Suami Dengan Tingkat Kecemasan Istri Dalam Menghadapi Menopause Di Wilayah Kerja Polindes Tebalo Manyar Gresik. Skripsi. Universitas A irlangga. Retrieved from http://repository.unair.ac.id/23836/

Varneym H, M.Kriebs J, Gegor CL. (2010). Nutrisi selama menopause dan sesudahnya: Jakarta.

Widjayanti, Y. (2016). Gambaran Keluhan Akibat Penurunan Kadar Hormon Estrogen pada masa Menopause. Adi Husada Nursing Journal, 2(1). 